\title{
Exploring the Impact of the COVID-19 Pandemic on Rural English FAL Teachers' Lesson Planning
}

\author{
Mosebetsi Mokoena \\ School of Social Sciences and Language Education \\ Faculty of Education \\ University of the Free State, QwaQwa Campus \\ Bloemfontein, South Africa \\ Corresponding Author: M.rmokoenams@gmail.com
}

Received: $11 / 29 / 2021$

Accepted:1/10/2022

Published: $1 / 24 / 2022$

\section{Abstract}

The Coronavirus (COVID-19) has disrupted the process of teaching and learning in various ways. In particular, lesson planning in rural English first additional language (FAL) classrooms has been disrupted. As a result, there is a need to explore the impact of the COVID-19 pandemic on rural English FAL teachers' lesson planning. To achieve this aim, these questions remain central to this study: How does the COVID- 19 pandemic disrupt the typical teaching plans of English FAL teachers in a rural context? How do rural English FAL teachers respond to the challenges of the phased- in and rotational approaches during the COVID-19 pandemic? The study follows a qualitative research design and uses Document Analysis to generate data from the eleven participants whose responses are analyzed thematically. The findings reveal that rural English FAL teachers face challenges when planning lessons amid the COVID-19 pandemic. These include: struggle with committing to the plan, inadequate coverage of content, catering for learners' educational needs, as well as learner-absenteeism and the need for re-teaching. The paper recommends the following strategies for rural English FAL teachers to circumvent these challenges. They include: incorporating various resources in the lesson plan, integrating active learning activities in the lesson plan, and tailoring lesson plans to meet learners' educational needs.

Keywords: covid-19 pandemic, english language teaching, impact, lesson planning, rural teachers

Cite as: Mokoena, M. (2022). Exploring the Impact of the COVID-19 Pandemic on Rural English FAL Teachers' Lesson Planning. Arab World English Journal (AWEJ) $2^{\text {nd }}$ Special Issue on Covid 19 Challenges (2) 479- 491.

DOI: https://dx.doi.org/10.24093/awej/covid2.32 


\section{Introduction}

The continuous spread of the Coronavirus (COVID-19) has been signifying changes in the teaching and learning spaces since December 2019 (Fatima, 2020; Yi \& Jang, 2020; Chu et al., 2021). In some instances, school closures became inevitable while alternative ways and opportunities were explored in other instances (Xhaferi \& Xhaferi, 2020). The need to ensure continuous educational activities amid the pandemic necessitated many countries to adopt online education. Similarly, South Africa adopted and promoted remote learning in response to the COVID-19 pandemic. However, this move brought various challenges, especially for teachers and learners in rural schools. People in urban areas have significant access to online education than those in rural ones (Landa et al., 2021). This is important considering that many learners stay and attend school in the latter areas. The problem of limited access to the internet came to the fore as 90 percent of the households lack access to the internet (Statistics South Africa, 2020). Teachers in many South African rural schools lack the skills required to facilitate online learning and teaching due to minimal or no training (Monareng et al., 2020). Apart from this skills gap in information communication technology (ICT) knowledge (De Klerk \& Palmer, 2021), rural schools lack the necessary resources and equipment necessary for the successful implementation of remote learning (SAST, 2020; Mukuna \& Aloka, 2020). The high cost of data has been another problem facing teachers and learners in schools situated in rural areas (Monareng et al., 2020) across the country. The erratic fluctuations in internet speed and connectivity exacerbate this situation (Kamble et al., 2021).

In an attempt to avoid further disruptions to the academic program, the Department of Basic Education (DBE) introduced several intervention strategies. First, schools adopted the 'phased-in' as well as 'rotational' approaches in an attempt to salvage the academic year. In other words, learners returned to school according to the different phases they belonged to, or they had to attend on a rotational basis. Second, the DBE devised a curriculum recovery plan for all schools. The plan focused on three main areas:

- The reorganization and trimming of the curriculum;

- $\quad$ The amendment of the existing annual teaching plan; and

- $\quad$ Retaining of fundamental skills and critical concepts (Mohale et al., 2020).

Although the above strategies may have succeeded in curbing the spread of the COVID19 pandemic in schools, lesson planning and preparation in rural English FAL classrooms have been negatively affected. In light of the challenges relating to online learning in rural schools and the digital divide that exists between urban and rural schools (Dube, 2020), it became difficult for both teachers and learners "to adapt themselves to a very new and highly innovative method of teaching" (Fatima, 2020, p. 2). In other words, rural English FAL teachers did not receive guidelines from the DBE that they could use to design, prepare and implement their teaching plans in response to the trimmed curricular, rotational and phased-in approaches necessitated by the COVID-19 pandemic. This paper acknowledges the importance of the curriculum recovery plan and its aims, while it argues that the plan is not a panacea as individual teachers have the ultimate responsibility of implementing it in their classrooms.

This implementation requires thorough lesson planning and preparation. This critical aspect of the teaching process becomes even more difficult considering the phased-in and 
rotational approaches under which schools currently operate. This situation fails to provide teachers with sufficient time necessary for effective lesson planning. In this case, Van der Walt, Evans and Kilfoil (2014) remind us about the time teachers need for conceptualization and visualization of the intended lesson. In addition to this, these authors link sufficient planning time to effective lesson preparation and delivery. This view raises a few pertinent questions: how can educators in poorly resourced schools plan their lessons effectively during a pandemic? Secondly, how do English FAL teachers plan their lessons effectively within a limited period exacerbated by the COVID-19 pandemic?

This paper, therefore, explores how Covid-19 affects the lesson planning and preparation for rural English FAL teachers. This aspect may be taken for granted for teachers in well-resourced schools because learners and teachers have access to technological devices. The same, however, cannot be true with English FAL teachers in rural spaces where there is "a lack of resources to connect to the internet, the learning management systems, and low tech-software" (Dube, 2020, p. 135). The Covid-19 pandemic exacerbates this situation. As a result, rural English FAL teachers need to be innovative and creative when planning and preparing their lessons. Therefore, this study reflected on the following questions:

- How did the COVID- 19 pandemic disrupt the typical teaching plans of English FAL teachers in a rural context?

- How did rural English FAL teachers respond to the challenges of the phased-in and rotational approaches during the COVID-19 pandemic?

While there is a plethora of literature around lesson planning and preparation, the studies investigating how the Covid-19 pandemic has affected lesson planning and preparation in rural contexts remain limited. This study, therefore, attempts to address this gap in research.

\section{Teachers' lesson planning}

A common understanding of lesson planning and how it is carried out have been challenging for scholars (Bieda, Lane, Evert, Hu, Opperman \& Ellefson, 2020). In fact, there is limited research on this critical aspect of teaching and learning (Waks, 2019). Given this complexity, the individual teacher cognitive process, and an ecologically situated framework are two perspectives that have dominated the research on this concept. Research on the first perspective focuses mainly on the cognitive processes a teacher engages in while planning their lessons (Beida et al., 2020). This process results in the amount of time allocated for each activity, lesson activities and classroom routine. Other scholars direct their effort in understanding teachers' beliefs, instructional goals, and knowledge of content and their roles when planning a lesson (Hill et al., 2008). For Remillard and Heck (2014), lesson planning begins the curriculum enactment process. In this regard, the focus is on a teacher-intended curriculum that involves individual teacher's interpretations and decisions relating to the planning of the lesson, referred to as an official curriculum. Here, the aims, objectives, content, and assessment of the actual curriculum are considered (Beida et al., 2020).

Various models influence the development of lesson planning. Firstly, Tyler's (1949) work depicts the earlier understanding of lesson planning. While the model adopts an outcomesbased approach, specific observable objectives, learning experiences and evaluation of these 
experiences are critical (Zazkis, Liljedahl \& Sinclair, 2009). Although this model forms the basis of many lesson planning templates used in educational institutions, its rigidity and disregard for real-life situations in the classroom drew criticism (Black, Lawson, \& Norwich, 2019). These templates are a threat to the professionalization of teaching (Hurst 2020). Secondly, the consideration of teachers' beliefs and assumptions about what learners' educational needs are served as a new model alternative to the one proposed by Tyler. The flexibility of this model creates a space for objectives and activities to align (John, 2006).

Despite these diverse viewpoints, lesson planning is defined in various ways. A lesson plan contains the teachers' intentions and the means of attaining such outcomes at the end of the learning experience (Thornbury, 2006 cited in Van der Walt et al, 2014). When conceptualizing a lesson plan, Van der Walt et al, (2014) distinguish between planning and preparing. The former appeals to the teacher's cognitive ability and creativity when deciding on learning content and various teaching methods. The latter involves the actual steps the teacher takes to ensure effective lesson presentation and attainment of lesson outcomes.

\section{Lesson planning in the context of English first additional language}

The Curriculum and Assessment Policy Statement (CAPS) requires English FAL educators to plan for a two-week cycle. In this plan, teachers need to integrate the four language skills: listening and speaking, writing and presenting, reading and viewing, as well as language structures and conventions (DBE, 2011). Additionally, English FAL teachers are expected to plan for over 36 weeks. The plan focuses on building context, consolidating vocabulary and mastering aspects of grammar and language structures progressively. Although the emphasis is on teaching these four skills in an integrated manner, rural English FAL teachers do not plan and teach these skills in a particular order. Moreover, English FAL teachers are given flexibility to choose literary texts as part of the reading and viewing skills.

When producing these guidelines for teaching plans, it should be noted that this was done with no anticipation of any significant disruption such as COVID-19. As a result, rural English FAL teachers are expected to follow and implement the prescripts of the CAPS document to the letter when planning their lessons. However, this implementation requires thorough lesson planning and preparation in the face of the pandemic. This critical aspect of the teaching process becomes even more difficult considering the phased-in and rotational approaches under which schools currently operate. This situation fails to provide teachers with sufficient time that is necessary for effective lesson planning. Therefore, this paper explores how Covid-19 affects the lesson planning and preparation for rural English FAL teachers.

\section{Theoretical framework}

Critical Emancipatory Theory (CET) is adopted as a lens couching this study. The origins of CET could be traced back to Critical Theory (Creswell \& Creswell, 2017). The CET-anchored research aims to address social issues through emancipation, courage and empowerment of the participants (Gordon, 1986; Shor, 1988).

The relevance of CET for this study ties to the researcher's philosophical orientations, personal beliefs about the ontological and epistemological nature of knowledge. I subscribe to the transformative paradigms (such as CET), which acknowledge the existence of multiple 
realities when interrogating a phenomenon under study. In this regard, this study appreciates the important multiplicity of views held by the participants. While they are in-service teachers of English FAL in rural contexts, the unique experiences and lived realities shape the participants' responses in this study. As a result, they hold varying perceptions about lesson planning amid the COVID-19 pandemic. These rich and subjective experiences enhance their understanding of the challenges around lesson planning.

Similarly, central to transformative paradigms are notions of empowerment and emancipation. In this regard, knowledge is a product of collaborative efforts by both researchers and participants. In other words, the participants engage in the co-construction of this knowledge instead of being passive recipients. To this effect, they actively identified the various challenges they encountered in the planning, designing and executing their lessons in their respective English FAL classrooms. Instead of relying on solutions from the periphery, these teachers developed strategies to circumvent the challenges that the COVID-19 pandemic brought. In other words, they become empowered and can emancipate themselves from this situation.

\section{Methods}

Data was obtained from Bachelor of Education Honours students from one rural university. While pursuing postgraduate studies, these students are also in-service teachers of English FAL in rural schools across South Africa. Owing to their undergraduate course work which prepared them for lesson planning and preparation under 'normal' circumstances, it was necessary then to find out how the COVID-19 pandemic impacted on their planning.

\section{Participants and procedure}

There were eleven (11) participants in this study. All of them were registered for a postgraduate Language Education module and they were also in-service teachers of English FAL in various rural schools across South Africa. Apart from being students in this module, their suitability for this study stems from the fact that the Covid-19 pandemic affected their lesson planning and preparation. This was important, as obtaining such information would assist other teachers in similar situations to learn from the recommendations from this study.

The students were instructed to complete an assignment as part of their continuous assessment in one English Teaching module. This was an individual work in which students were asked to answer a set of questions about their lesson planning and preparation. They were then provided with the rubric that would be used to assess or grade their reflections. In this assignment, each student was instructed to continue planning and preparing for their English FAL lessons. While doing this, they should not break any of the COVID-19 Health protocols. Furthermore, they had to keep notes and make reflections after each lesson. These reflections were mainly about the challenges that they encountered while planning and executing their plans in their English FAL classrooms. In addition, they noted different strategies they used to circumvent the challenges posed by the COVID-19 pandemic.

\section{Measures and Data Analysis}

The study used Document analysis to generate data. Students were not provided with lesson plan templates because each school had its own. However, the expectation was that all lesson plans followed the prescripts set out in the CAPS document. At the end of three weeks, participants 
submitted their documents for analysis and grading. All the eleven participants submitted their written reflections via Blackboard. In all cases, the reflections were more than five pages long. This allowed students an opportunity to elaborate on their answers and to provide a variety of responses (Tsotetsi et al., 2020). To determine the originality of the responses, the assignments were subjected to Turnitin software. The participants reflected on the following questions:

- How did the COVID- 19 pandemic disrupt the typical teaching plans of English FAL teachers in a rural context?

- How did rural English FAL teachers respond to the challenges of the phased-in and rotational approaches during the COVID-19 pandemic?

The documents were retrieved from Blackboard for grading purposes. Later, these documents were re-read and analyzed thematically for the purposes of this study.

\section{Findings and discussions}

The findings revealed that COVID-19 negatively impacts on teacher lesson planning and preparation in rural English FAL classrooms. A thorough thematic analysis of the challenges exposed four (4) main themes from the participants' documents. These include, difficulty committing to the plan, inadequate coverage of content, learner-absenteeism and the need to reteach, and difficulty catering for the needs of English FAL learners. On the other hand, the following strategies proved helpful when planning lessons during the COVID-19 pandemic: incorporating various resources in the lesson plans, integrating active learning activities in the lesson plans, and, tailoring lesson plans to meet the learners' educational needs.

\section{Theme 1: Difficulty committing to the plan}

Under normal circumstances, lesson planning requires flexibility from the teacher. In other words, successful teachers review and revise their plans continuously during the lesson. While this may be viewed in a positive light, under the COVD-19 pandemic, however, this posed a challenge to the rural English FAL teachers, evident from their perceptions below:

TEACHER 1: My lessons never go as planned due to a variety of issues... a lack of understanding of the material, a decrease in teacher-learner communication...

TEACHER 3: In every lesson I have to do lesson plan but during this pandemic one plans and the plans changes anytime due to different circumstances caused by the Covid-19.

As shown in the preceding statements, rural English FAL teachers find it difficult to plan effectively. The difficulty comes from the struggle to plan for learners who may not come to school because of rotational and phased-in approaches. Another challenge involves finding teaching materials that could be used amid the Covid-19 safety protocols. This situation makes lesson planning challenging because many rural schools lack resources and learners often share learning materials. This results in constant changes to lesson planning. This is summarised in the statement captured below:

TEACHER 11: While I attempted to maintain learning continuity throughout this period, learners were forced to rely increasingly on their own resources to continue studying. 
Arab World English Journal (AWEJ) 2nd Special Issue on Covid 19 Challenges January 2022

Exploring the Impact of the COVID-19 Pandemic on Rural English FAL

Mokoena

Apart from finding appropriate teaching material, rural English FAL teachers find it challenging to stick to the lesson objectives.

TEACHER 3: Planning is very difficult because I have to think of the teaching strategies that will accommodate all learners without going against the Covid-19 rules.

TEACHER 9: I plan the activities, but I sometimes fail to accomplish their goals...

TEACHER 1: However, during Covid-19 objectives planned are not able to be achieved.

As captured in the statements by the two teachers above, the lesson planning and preparation is often done with a particular goal in mind. However, this becomes futile when the likelihood of achieving those goals seems impossible. In this case, the rotational and phase-in approaches exacerbated by the COVID-19 pandemic make it difficult for rural English FAL teachers to set clearly defined objectives of their lessons.

\section{Theme 2: Inadequate coverage of content}

Although the annual teaching plans are amended during the COVID-19 pandemic, content coverage has remained a challenge for rural English FAL teachers. The use of rotational and phased-in approaches complicates the situation. In this regard, rural English FAL teachers cannot cover the required content. In most cases, there is always a need to re-teach some aspects to learners who may have forgotten due to the disruption in their learning routine. These are captured in the statements below:

TEACHER 4: One lesson has to cover three days of teaching and learning because ATP has to be observed.

TEACHER 5: I have been ended up skipping annual teaching plan, some of the topics completed in two terms in a month so that I can cover my work...listening and speaking skills is about visual or multimedia text...remember I had to do it in two days' cycle but students come to school twice per week... I had to try to do it in 2 hours. I have to deal with the same topic for the whole week, and it has been a setback because I end up depriving my students of the actual content they had to learn...

Other participants identified insufficient time as another factor impeding content coverage during the lessons. In this case, the following remarks are noteworthy:

TEACHER 6: It became so challenging to prepare for a lesson that you are uncertain about whether it will [be] achievable or not during Covid-19...my preparations are not guaranteed anymore.

TEACHER 7: Learners were attending in two groups in order to keep social distancing of 1.5 meters in classrooms...I had to plan the same lesson for both groups...repeating one lesson for two weeks really wasted time because at the end of the term I could not finish what was expected of me to teach the learners. 
Arab World English Journal (AWEJ) 2nd Special Issue on Covid 19 Challenges January 2022

Exploring the Impact of the COVID-19 Pandemic on Rural English FAL

Mokoena

\section{Theme 3: Difficulty catering for the needs of English FAL learners}

Part of lesson planning requires teachers to consider using different teaching strategies for effective teaching and learning. These strategies are also used to cater for learners' different learning styles. However, this has proven difficult in rural English FAL classrooms within the Covid-19 context. In some cases, it is difficult to engage learners in activities that require group discussions. This is particularly important as it goes against the prescripts of CAPS which require active participation of learners in the classroom. This is captured in the comments below:

TEACHER 10: In the past, planning for lessons was more fun because as a teacher I had to play around with ideas...

TEACHER 5: It is also made things difficult for me since I could no longer have them do group work... it has been a setback because I end up depriving my students of the actual content they had to learn...

TEACHER 2: Planning is very difficult because I have to think of the teaching strategies that will accommodate all learners without going against the Covid-19 rules... it is almost impossible to accommodate all learners...even if I try to meet their needs, the time is very limited.

TEACHER 1: In my lesson planning I choose a specific teaching method such as role-play when reading, but how do we role-play with our small classes and need for social distancing? In addition to a lack of flexibility in lesson planning, the COVID-19 situation negatively impacts on rural English FAL teachers' creativity when planning and presenting their lessons. Perhaps more serious is the challenge of failing to cater to the different needs and learning styles of learners during the lesson. As stated by teacher 3 above, the existence of covid-19 safety protocols limits teachers' use of different teaching strategies.

\section{Theme 4: Learner absenteeism and the need for re-teaching}

Despite decreasing number of days learners spend in school, the COVID-19 pandemic seems to exacerbate learner absenteeism. As a result, this situation hinders effective lesson planning and preparation in many rural English FAL classrooms. In some instances, teachers cannot complete the syllabus on time as they sometimes have to re-teach the same lessons more than once. The following statements attest:

TEACHER 4: Absenteeism is a major problem and late coming of learners...

TEACHER 6: I end up failing to do a proper lesson plan, sometimes I fail to cover what is on the lesson plan because learners don't come to school daily... it affects me because I now use a same lesson plan two days or even three days.

In other instances, learner absenteeism negatively impacts on the quality of education that learners receive. In this regard, lessons are repeated continuously and this affects the learning and teaching of the new content. In others words, rural English FAL teachers do not have sufficient time to plan for the actual teaching of new content. Consequently, this information is presented haphazardly in the classroom. For instance, TEACHER 10 says: 
Arab World English Journal (AWEJ) 2nd Special Issue on Covid 19 Challenges January 2022

As a teacher...you have to rush to complete the syllabus instead of minding the child's progress...it is now about quantity over quality... however, due to COVID-19, the spontaneity and the eager of wanting to learn something new and teach learners that new information has been reduced.

TEACHER 5: I have to deal with the same topic for the whole week, and it has been a setback because I end up depriving my students of the actual content they had to learn....

TEACHER 4: One lesson has to cover 3 days of teaching and learning because ATP has to be observed.

Furthermore, assessment is an integral part of lesson planning. In other words, when deciding what learners will be taught, it is important also to determine ways for assessing whether or not the objectives of the lesson have been achieved. This enables the educator to reflect on the successes and failures of the lesson plan. However, increased learner-absenteeism due to the COVID-19 pandemic has affected this critical aspect of lesson planning. Specifically, English FAL teachers in rural schools find it challenging to infuse assessment in their lesson plans. Their challenges are summarised below:

TEACHER 6: Writing skill is achieved easily when learners are assessed but due to Covid-19, more learners don't come to school so even when I assess I only assess few learners...

TEACHER 2: Even if I try to meet their needs, the time is very limited...that will make it difficult for me as a teacher to see if all the students really understand what is expected of them.

TEACHER 11: Due to COVID-19 rules of not touching other objects, I plan, give them work but it becomes difficult for me to collect the books.

In addition to the challenges above, the analysis of participants' responses revealed several strategies they used to circumvent these challenges in their classrooms. In this regard, the following themes emerged:

\section{Theme A: Incorporating various resources in the lesson plan}

The COVID-19 pandemic makes it difficult for learners to bring and share resources in the classroom. However, the need to supplement and enhance the planning, preparation and execution of lessons, rural English FAL teachers brought their resources in the classroom. While cautious to the threats posed by COVID-19, they used these resources to clarify some difficult concepts in the classroom. Teacher 1 and Teacher 2 elaborate:

TEACHER 1:But the use of different pictures, letters or words on the wall linking to the lesson makes learners more determined to understand as we are talking about what they see.

TEACHER 2: Bringing extra resources in class, using variety of lived experiences as examples, and writing notes for them to go read at home.

TEACHER 9: I also use visual aids more because they help learners to understand what is being said more clearly 
Arab World English Journal (AWEJ) 2nd Special Issue on Covid 19 Challenges January 2022

Exploring the Impact of the COVID-19 Pandemic on Rural English FAL

Mokoena

TEACHER 6: I used puppets to tell a story, bin bag to keep them interested...

As stated above, incorporating various resources in lesson planning and preparation proved helpful in several ways. It assisted in enhancing learners' understanding of the content presented in class. In other words, these resources helped to ensure that these teachers achieved the objectives of the lessons.

\section{Theme B: Integrating active learning activities in the lesson plan}

The COVID-19 pandemic and the associated health and safety protocols discourage active and cooperative learning in the classrooms. In turn, this requires rural English FAL teachers to plan their lessons around activities that support teacher-centered pedagogical practices. These practices contradict the prescripts of CAPS which encourage active learning. In addition, teachers in a teacher-centered classroom do not vary teaching strategies. This makes learning a tedious and monotonous process as learners are rendered passive recipients of knowledge. In response to this situation, rural English FAL teachers incorporated activities that required active participation without the risk of spreading the COVID-19 virus in the classroom. Teacher 2 states:

Giving learners practical examples, and allow them to come up with their own examples makes the lesson fun and majority of learners partake... I allow them to read in rows or in- play I characterize them by their rows. The whole row will be one character and read the lines of that particular character.

TEACHER 10: Due to time against curriculum coverage, I group learners according to abilities to keep momentum of teaching and learning at the same pace. I use small groups in my advantage to give each child attention rather than in a large classroom.

TEACHER 11: It is compulsory that a teacher prepares learners for a lesson by making them sing rhymes and poems

The incorporation of various strategies lesson plans to promote active learning and participation assisted in addressing the time factor which impacts negatively on the teachers' chances of completing the syllabus. In other words, incorporating activities that require active participation of learners contributes to meaningful learning. This also addressed the challenge of limited coverage of content.

\section{Theme C: Tailoring lesson plans to meet learners' needs}

As argued elsewhere in this paper, rural English FAL teachers are not equipped with strategies to plan their lessons effectively amid the COVID-19 pandemic. The pandemic brings the needs and challenges specific to learners in rural contexts. In most cases, as discussed above, these needs are neglected when teachers plan for the lessons. However, the teachers in this study responded to the challenge of meeting learners' educational needs through effective lesson planning. Below are some of the reflections from rural English FAL teachers:

TEACHER 5: To ensure all skills are executed properly I avoid having too many texts for them but focus on one text for all skills in a lesson. 
Arab World English Journal (AWEJ) 2nd Special Issue on Covid 19 Challenges January 2022

Exploring the Impact of the COVID-19 Pandemic on Rural English FAL

Mokoena

TEACHER 3: So narrow down my list to two or three language skills I want learners to learn in the lesson.

TEACHER 1: During this pandemic, I don't cover all the contents required in the curriculum but rather the trimmed content that is required.

TEACHER 8: I got used to planning according to the abilities of my learners, if they struggle with a certain lesson I address it again.

In this regard, they found ways of tailoring and adapting their lessons to accommodate and alleviate the challenges facing learners in the classrooms. In some cases, English FAL teachers trimmed the curricular even further by focusing on what they deemed important for learners to learn. This way, they could overcome the challenge of not completing sufficient content as needed.

\title{
Conclusion
}

Based on the inferences from the data, theories and literature explored in this study, lesson planning and preparation proved complex in rural English FAL classrooms due to the COVID-19 pandemic and the absence of guidelines assisting rural English FAL teachers in planning their lessons effectively amid this pandemic. While this paper acknowledges the importance of the curriculum recovery plan and its aims, data gathered in this study point to the difficulties rural English FAL teachers encountered when planning and preparing for their lessons. As argued, the absence of clear guidelines necessary for rural English FAL teachers to navigate through rotational and staggered approaches amplify these challenges. Furthermore, this paper does not argue for complacency towards the COVID-19 pandemic, but it elucidates challenges experienced by rural English FAL teachers when planning and preparing for the lessons. As the above analysis shows, while the COVID-19 pandemic exacerbates the challenges relating to lesson planning in rural English FAL classrooms, it also shows the resilience of rural English FAL teachers amid the pandemic. In this regard, they devised strategies to overcome these challenges. Although COVID-19 has been given the pandemic status, it is important, however, to caution against the generalization of the challenges experienced and strategies used by the English FAL teachers in other rural classrooms.

\begin{abstract}
About the Author:
Mosebetsi Mokoena holds a Ph.D. in Curriculum Studies. He is a lecturer at the University of the Free State. His research interests include English language teaching and learning, rurality, school enrichment programmes, and participatory action research in rural spaces. https://orcid.org/0000-0002-1541-9176
\end{abstract}

\section{References}

Akhter, T. (2020). Problems and Challenges faced by EFL students of Saudi Arabia during COVID-19 pandemic. Rupkatha Journal on Interdisciplinary Studies in Humanities, 12(5):1-7.

Bieda, K.N., Lane, J., Evert, K., Hu, S., Opperman, A. \& Ellefson, N. (2020). A large-scale study pf how districts' curriculum policies and practices shape teachers' mathematics lesson 
Arab World English Journal (AWEJ) 2nd Special Issue on Covid 19 Challenges January 2022

Exploring the Impact of the COVID-19 Pandemic on Rural English FAL

Mokoena

planning. Journal of Curriculum Studies, 52,(6), 770-799, DOI: $10.1080 / 00220272.2020 .1754921$

Black, A., Lawson, H. \& Norwich, B. (2019). Lesson planning for Diversity. Journal of Research in Special Education Needs, 19,(2), 115-125.

Chu, A.M.Y., Liu, K.W.C., So, M.K.P. \& Lam, B.S.Y. (2021). Factors for Sustainable Online learning in Higher Education during the COVID-19 Pandemic. Sustainability, (13), 5038.

Creswell, J. W., \& Creswell, J. D. (2017). Research design: Qualitative, quantitative, and Mixed methods Approaches. Sage publications.

De Klerk, E.D. \& Palmer, J.M. (2021). Resetting Education priorities during COVID-19: Towards Equitable learning opportunities through Inclusion and Equity. Perspectives in Education, 39,(1), 12-28.

Department of Basic Education (DBE). (2011). National Curriculum Statement: Curriculum and Assessment Policy Statement (CAPS). Government Printing word

Dube, B. (2020). Rural Online Learning in the context of COVID-19 in South Africa: Evoking an Inclusive Education Approach. Multidisciplinary Journal of Educational Research, 10, (2), 135-157.

Fatima, N. 2020. English language teaching during the times of COVID-19 Challenges and Opportunities: A brief study of GFP students in Muscat College. Journal for Research Scholars and Professionals of English Language Teaching, 21,(4),1-6.

Gordon, B. M. (1986). The use of Emancipatory Pedagogy in Teacher Education. The Journal of Educational Thought (JET)/Revue De La Pensée Éducative, 2,(4), 59-66. doi.org/10.18297/etd/3160

Hill, H. C, Ball, D. L, \& Schilling, S. G. (2008). Unpacking pedagogical content knowledge: Conceptualizing and Measuring teachers' topic-specific knowledge of students. Journal for Research in Mathematics Education, 39,(4), 372-400.

Hurst, H. (2020). Inspired Alchemy: Reconceptualising lesson planning as Creative Work. English Education, 53,(1), 94-100.

John, P. (2006). Lesson planning and the Student Teacher: Re-thinking the Dominant Model. Journal of Curriculum Studies, 38, (4), 483-98.

Kamble, A., Gauba, R.; Desai, S. \& Golhar, D. (2021). Learners' Perceptions of the transition to instructor-led Online learning environments: Facilitators and Barriers during the COVID19 Pandemic. International Review of Research in Open and Distributed Learning, 22,(1), 200-215.

Landa, N., Zhou, S. \& Marongwe, N. (2021). Education in Emergencies: Lessons from COVID19 in South Africa. International Review of Education, (67), 167-183.

Lysaght, Z. (2011). Epistemological and Paradigmatic ecumenism in "Pasteur's Quadrant:" Tales from doctoral research. Official Conference Proceedings of the Third Asian Conference on Education. Osaka: Japan.

Mohale, A.B.; Litshani, N.F., Mashau, T.S., Mudau, T.J., Moyo, H. \& Sebopetsa, N.S. (2020). The Impact of COVID-19 Pandemic on the Implementation of Curriculum Recovery Plan in Mopani district, Limpopo Province. Gender \& Behaviour, 18,(4), 16602-16617.

Monareng, J., Ramraj, A.B. \& Mashau, P. (2020). The Rise in Online learning in South African schools due to the Coronavirus Pandemic. Gender \& Behaviour, 18,(4), 16753-16762.

Mukuna, K.R. \& Aloka, P.J.O. (2020). Exploring Educators' challenges of Online learning in COVID-19 at a Rural school, South Africa. International Journal of Learning, Teaching and Educational Research, 19,(10), 134-149. 
Arab World English Journal (AWEJ) 2nd Special Issue on Covid 19 Challenges January 2022

Osanloo, A., \& Grant, C. (2014). Understanding, Selecting, and Integrating a theoretical framework in Dissertation Research: Creating the blueprint for your "house". Administrative issues journal: connecting education, practice, and research, 4,(2), 12-26. doi.org/10.5929/2014.4.2.9

Remillard, J. T., \& Heck, D. J. (2014). Conceptualizing the Curriculum enactment process in Mathematics Education. ZDM, 46,(5),705-718. https://doi.org/10.1007/s11858-0140600-4

Shor, I. (1988). Working Hands and Critical Minds: A Paulo Freire Model for Job Training. The Journal of Education, 170,(2), 102-121. doi.org/10.1177/002205748817000206.

Tyler, R. (1949). Basic Principles of Curriculum and Instruction. Chicago, IL: University of Chicago Press.

Van der Walt, C., Evans, R. \& Kilfoil, W.R. (2014). Learn 2 teach: English language teaching in a Multilingual Context $\left(4^{\text {th }}\right.$ ed.). Pretoria: Van Schaik Publishers

Waks, L.J. (2019). Guiding intuitions in education: Lesson planning as Consummatory Experience. Education and Culture, 35,(2), 27-46.

Xhaferi, B. \& Xhaferi, G. (2020). Online learning Benefits and Challenges during the COVID-19 Pandemic: Students' Perspective from SEEU. SEEU Review, 15,(1), 186-103.

Yi, Y. \& Jang, J. (2020). Envisioning possibilities amid the COVID-19 pandemic: Implications from English language in South Korea. TESOL

Zazkis, R., Liljedahl, P. \& Sinclair, N. (2009). Lesson plays: Planning teaching versus Teaching planning. For the Learning of Mathematics, 29, (1),4:40-47. 